\title{
C7 extension crosswise osteotomy: a novel osteotomy for correction of chin-on-chest deformity in a patient with ankylosing spondylitis
}

\author{
Andrzej Maciejczak, MD, PhD, ${ }^{1,2}$ Andzelina Wolan-Nieroda, $\mathrm{PhD},{ }^{2}$ and Agnieszka Guzik, $\mathrm{PhD}^{2}$ \\ ${ }^{1}$ Department of Neurosurgery, St. Lukas Hospital, Tarnów; and 2Medical Faculty, University of Rzeszów, Poland
}

Extension crosswise osteotomy at $\mathrm{C} 7$ (C7 ECO) was developed for the correction of forward gaze in patients with chinon-chest deformity due to ankylosing spondylitis. A modification of cervicothoracic extension osteoclasis (C/T EO), C7 ECO replaces osteoclasis of the anterior column with a crosswise cut of the $\mathrm{C} 7$ vertebral body to eliminate the risks of unintended dislocation of the cervical spine. $\mathrm{C7} \mathrm{ECO}$ also eliminates the risks of $\mathrm{C7}$ and $\mathrm{T} 1$ pedicle subtraction osteotomies (C/T PSOs), in which a posteriorly based wedge excision may lead to stretching injuries of the lower cervical roots and/or failure to achieve the exact angle of excision required for an optimal correction. Furthermore, opening the osteotomy anteriorly, as in the authors' method, instead of closing it posteriorly, as in PSO, eliminates the risks related to shortening of the posterior column, such as buckling of the dura, kinking of the spinal cord, and stretching of the lower cervical nerve roots. Here, the authors report the use of $\mathrm{C7}$ ECO for the surgical treatment of a 69-year-old man with severe compromise of his forward gaze due to chin-on-chest deformity in the course of ankylosing spondylitis. After uneventful correction surgery, the patient regained the ability to see objects, namely faces of people, at the level of his head while standing and to perform work tasks at a desk.

https://thejns.org/doi/abs/10.3171/2020.7.SPINE20258

KEYWORDS cervicothoracic pedicle subtraction osteotomy; cervicothoracic osteoclasis; chin-on-chest deformity; cervical kyphosis; ankylosing spondylitis; thoracic

$\mathrm{E}$ XTENSION crosswise osteotomy AT C7 (C7 ECO; Fig. 1 left) is a modification of C7-T1 cervicothoracic extension osteoclasis (C/T EO). A C7 ECO is performed with a crosswise cut of the $\mathrm{C} 7$ vertebral body rather than osteoclasis of the anterior column used in $\mathrm{C} / \mathrm{T}$ EO. The crosswise cut in C7 ECO eliminates the risks carried by osteoclasis, namely unintended dislocation of the cervical spine..$^{1-9}$ Our modification also eliminates the risks carried by $\mathrm{C} 7$ and $\mathrm{T} 1$ pedicle subtraction osteotomies (C/T PSOs), the most frequently used osteotomies for the correction of chin-on-chest deformities. These risks are related to the shortening of the posterior column produced by closure of the posterior osteotomy and may include buckling dura, kinking of the spinal cord, and stretching injuries in the lower cervical nerve roots produced by pressure from the $\mathrm{C} 6$ or $\mathrm{C} 7$ pedicles (Fig. 1 right). ${ }^{10-12} \mathrm{C} / \mathrm{T}$ PSO requires retraction of the nerve roots during the excision of the posteriorly based wedge in the vertebral body and therefore carries an inherent risk of nerve root injury. A simple crosswise cut through the C7 vertebral body, as in our modification, eliminates the need for nerve root retraction and therefore reduces the risk of their iatrogenic injury.

\section{Case Report}

We report the case of a 69-year-old male patient seeking a surgical solution for severe compromise of his forward gaze, oral feeding, and hygiene of the neck due to chin-on-chest deformity developed during the course of ankylosing spondylitis (AS; Fig. 2A and C). The patient's preoperative chin-brow vertical angle (CBVA) was $50^{\circ}$. The patient expected to regain the ability to see objects, namely faces of people, at the level of his eyes while standing and to perform desk work tasks, namely reading documents, performing handwriting, and operating a computer from a sitting position.

Preoperative Preparations

Preoperative preparations included calculating the de-

ABBREVIATIONS AS = ankylosing spondylitis; CBVA = chin-brow vertical angle; $\mathrm{C} / \mathrm{T}=$ cervicothoracic; $\mathrm{ECO}=$ extension crosswise osteotomy; EO = extension osteoclasis; PSO = pedicle subtraction osteotomy.

SUBMITTED February 22, 2020. ACCEPTED July 1, 2020.

INCLUDE WHEN CITING Published online November 20, 2020; DOI: 10.3171/2020.7.SPINE20258. 


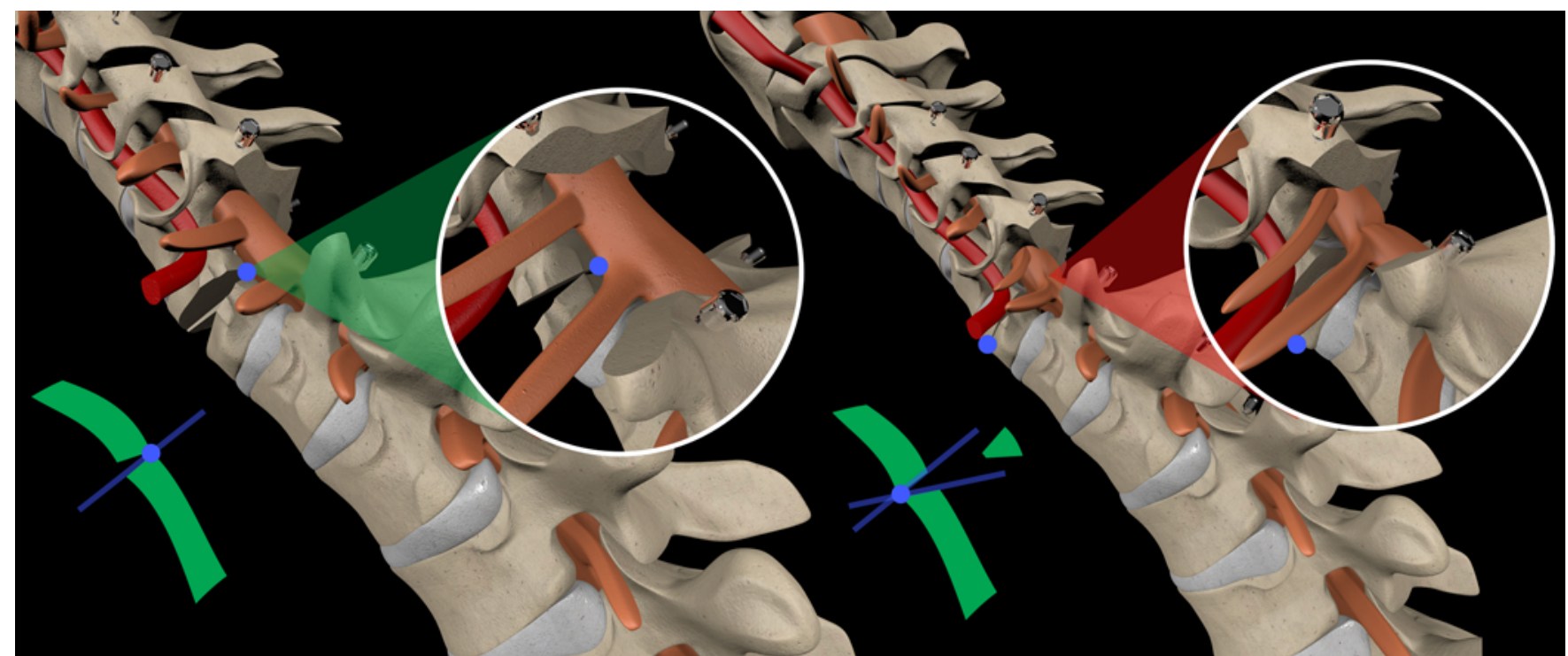

FIG. 1. Opening (left) versus closing (right) osteotomy. Opening osteotomy was achieved with C7 ECO (left inset), a novel osteotomy we suggest for the correction of chin-on-chest deformity. In contrast to opening osteotomy, PSO may carry risks of buckling of the dura, kinking of the spinal cord, and stretching of lower cervical nerve roots within the created common neuroforamen (right inset). Blue dots represent a hinge of opening (left inset) and closing (right inset) osteotomy.

sired postoperative CBVA and performing a positioning trial on the operating table with the patient awake and an anesthesiologic assessment regarding the optimal intubation technique. The following data were used to calculate the value of the postoperative CBVA: 1) trajectory of the normal (natural) vision line: $15^{\circ}$ downward inclination relative to the Frankfort line (Fig. 3); 2) vertical range of the near peripheral visual field: $60^{\circ}$, comprised of $30^{\circ}$ above and $30^{\circ}$ below the normal vision line (Fig. 4B); and 3) maximum eye elevation of $27^{\circ}$ and maximum eye depression of $45^{\circ}$ (Fig. 4A and C). Calculations were based on regular side photographs of the patient standing in a

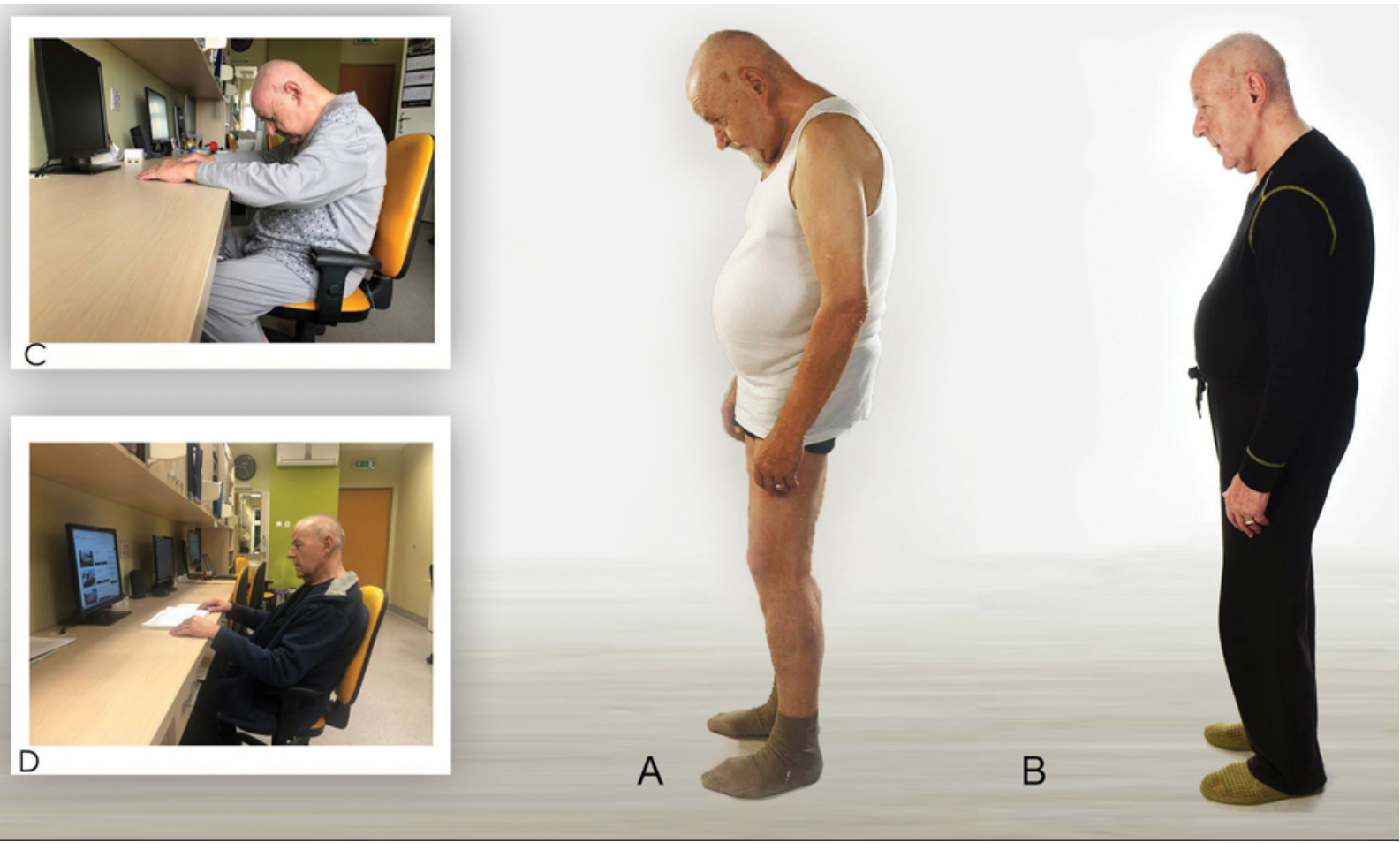

FIG. 2. Photographs of the patient before surgical correction in standing $(\mathbf{A})$ and sitting $(\mathbf{C})$ posture and after surgical correction in standing (B) and sitting (D) posture. Figure is available in color online only. 


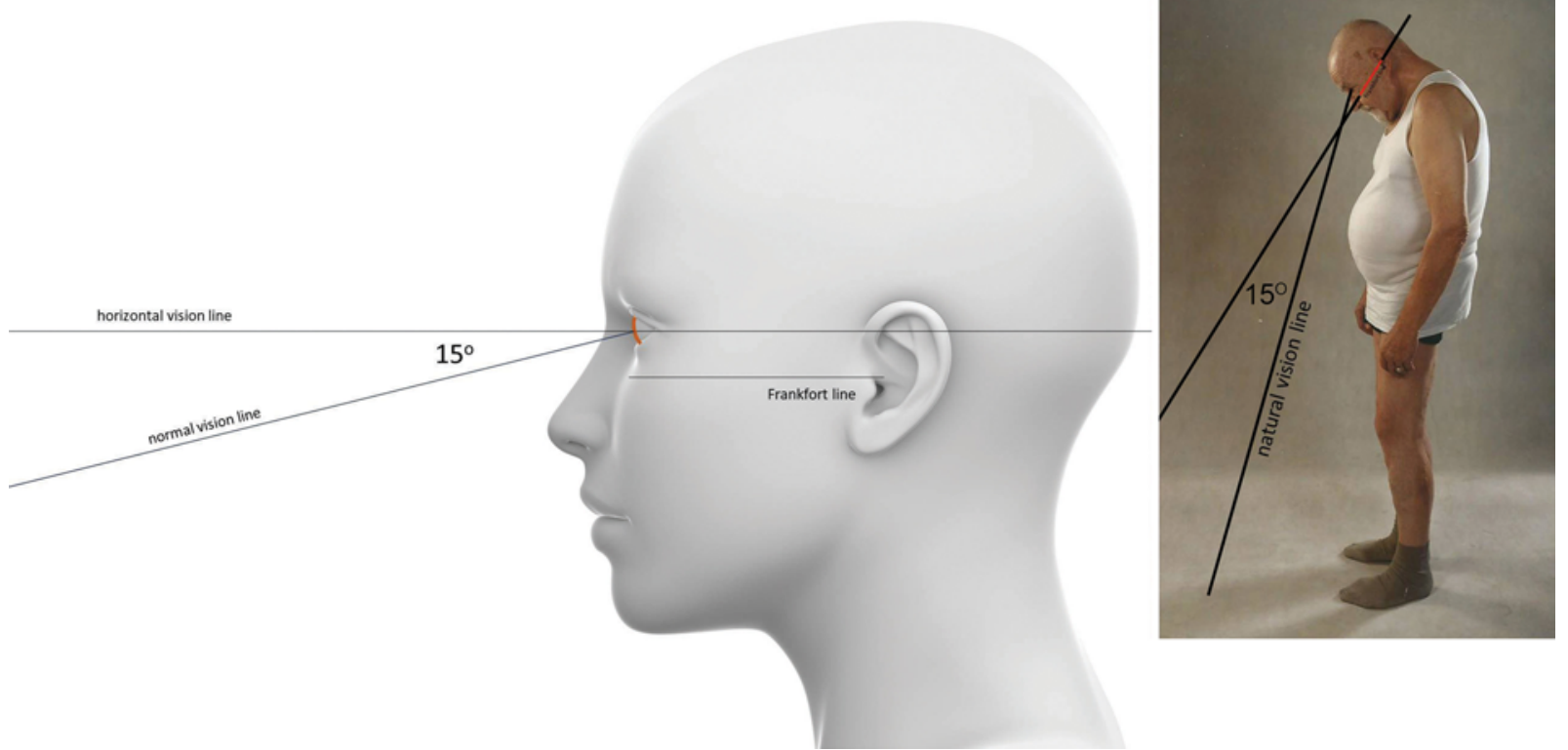

FIG. 3. Natural vision line. In a normal individual (left) the natural or normal line of vision is inclined $15^{\circ}$ downward from the Frankfort line, which is more or less parallel to horizontal. The patient's natural vision line before surgery (right inset). Figure is available in color online only.

neutral posture and sitting at a desk. Simulation with the use of Adobe Photoshop CS6 software showed that a postoperative $25^{\circ} \mathrm{CBVA}$ would provide the forward gaze improvement expected by the patient (Fig. 4). Target CBVA values can be obtained using preoperative whole-spine radiographs, including the skull, and Surgimap software.

A few weeks before surgery, the patient was invited to the hospital for a trial of positioning on the operating table while awake. Because the C/T spine is oriented vertically in the prone position in AS patients, it can be very difficult to center radiograph acquisition under O-arm navigation. In addition, the widespread base unit of the Mayfield clamp hampers positioning of the patient's $\mathrm{C} / \mathrm{T}$ spine in the acquisition zone. Thus, centering acquisition on the operated part of the spine can be time consuming and require multiple trials of both repositioning the patient and reassembly of the head holder system. Positioning an anesthetized patient with AS always carries a risk of inadvertent fracture of the spine at any level. This risk increases with multiple trials of positioning. Therefore, we performed a trial with an awake and cooperating patient to determine the optimal setup of the head holder and O-arm gantry and the patient's position on the operating table well before surgery. This setup can be documented with a regular photograph and replicated on the day of surgery.

Finally, due to limited range of mouth opening and
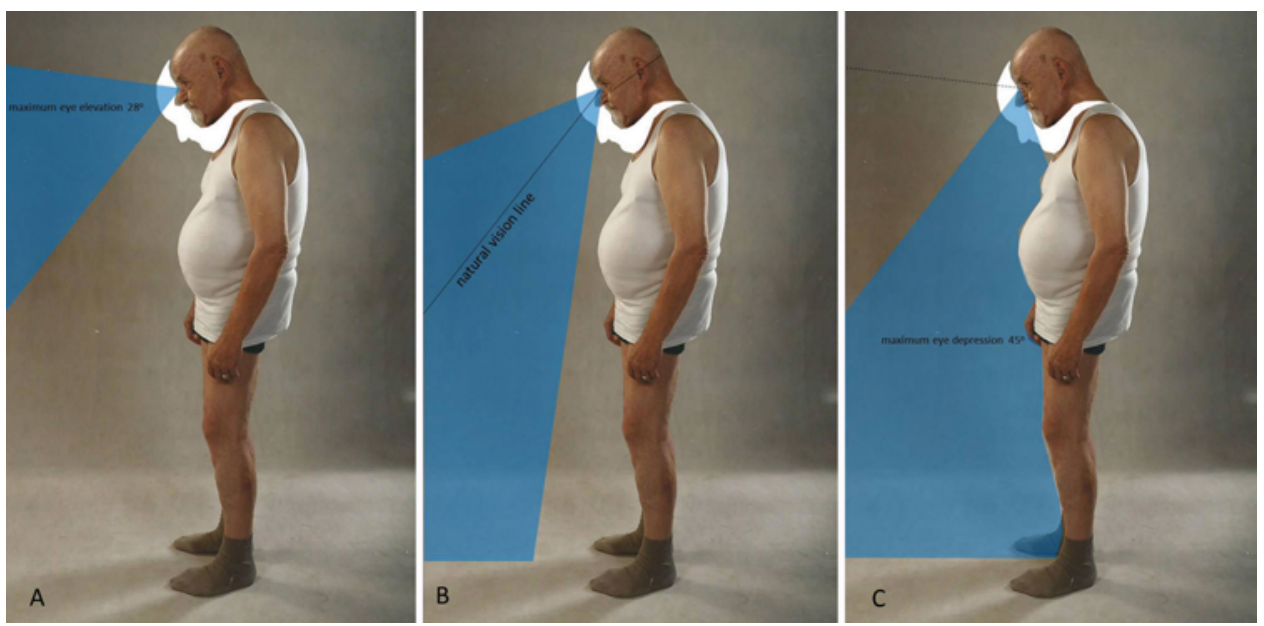

FIG. 4. Simulation of forward gaze after theoretical correction of cervical kyphosis by $25^{\circ}$. A: With maximum eye elevation of $27^{\circ}$, the patient is able to direct the natural vision line and near-peripheral visual field (triangular shadow) more forward and achieves the ability to see objects at the level of his eyes. B: The patient's natural line of vision and near-peripheral visual field after correction. C: With maximum eye depression of $45^{\circ}$, the patient is able to control his downward view. 
extreme flexion of the head, patients with AS qualify for conscious transoral or transnasal bronchofiberscope-assisted intubation.

\section{Surgical Technique of $\mathrm{C} 7 \mathrm{ECO}$}

The C7 ECO surgical technique performed on the patient, which was developed for the correction of forward gaze in a chin-on-chest deformity due to AS, is shown in Videos 1 and 2.

VIDEO 1. Animation of $\mathrm{C7} \mathrm{ECO}$ and differences between opening and closing wedge osteotomies. Copyright Andrzej Maciejczak. Used with permission. Click here to view.

VIDEO 2. Intraoperative video of C7 ECO. On-screen text describes anatomical details of the operative field and stages of surgery, from instrumentation through osteotomy until opening osteotomy through head extension. Copyright Andrzej Maciejczak. Used with permission. Click here to view.

The patient underwent transoral conscious intubation via bronchofiberscope and was positioned prone on the operating table with his head secured in a Mayfield clamp. O-arm navigation and neuromonitoring were used throughout the surgery. The use of navigation allows for orientation in the topography of the operating field and the anatomy of the spine, which can be distorted in AS. The beginning of the C7 ECO procedure was the same as in C/T EO and C/T PSO and included instrumentation of the spine using pedicle screws and osteotomy of the posterior elements. Similarly to instrumentation used in $\mathrm{C} / \mathrm{T} \mathrm{EO}$ and $\mathrm{C} / \mathrm{T} \mathrm{PSO}$, the instrumentation in this patient extended three levels below and above the osteotomy site and included the C4, C5, C6, T1, T2, and T3 vertebrae. The posterior osteotomy included resection of the $\mathrm{C} 7$ lamina, the lower edge of C6, and the upper edge of the T1 lamina, followed by a C6-T1 facetectomy with exposure of the $\mathrm{C} 7$ and $\mathrm{C} 8$ nerve roots in the neural foramina, and removal of $\mathrm{C} 7$ pedicles. Our modification began after the completion of the osteotomy of the posterior elements. We continued the osteotomy through the anterior column with a crosswise cut of the $\mathrm{C} 7$ vertebral body, instead of forcing osteoclasis, as in $\mathrm{C} / \mathrm{T} \mathrm{EO}$, or resection of the posteriorly based wedge, as in C/T PSO. The keys for the crosswise cut of the vertebral body are the following: 1) removal of both pedicles and 2) extremely wide exposure of the spine to the sides. The former opens access to the lateral portion of the posterior wall of the vertebral body. The crosswise cut was executed with the use of a fine chisel through this portion of the posterior wall at the level of the removed pedicles and between the C7 and C8 nerve roots. Such a cut does not require retraction of the nerve roots or their manipulation. Wide exposure of the spine to the sides allows the midline of the vertebral body to be reached with the chisel at a high angle from both sides of the spinal cord. In addition, the wide exposure opens access to the lateral walls of the vertebral body, as in PSO.

Once the vertebral body and its lateral walls were largely cut through, the anterior cortex was taken down with a fine Kerrison bone punch to avoid injury to prevertebral tissues, namely the esophagus. A fine Kerrison can be easily passed through the transverse cut in the vertebral body and its lateral walls reaching the anterior cortex. Once the osteotomy of the anterior cortex was completed, the oper- ating surgeon had to cut the posterior cortex left behind the anterior aspect of the dural sac. To cut the posterior cortex and avoid injury to the spinal cord, the chisel must be passed behind the anterior dura from the far lateral direction and at a high angle. With ample exposure of the spine to the sides, a surgeon can access the midline of the posterior cortex. If, however, the midline remnants of the posterior cortex are left in place, they can be safely broken during extension of the head. Once the three-column osteotomy was completed, rods were inserted into the heads of the thoracic screws and secured with tightening nuts. The operating surgeon grasped the Mayfield clamp under the drapes with one hand and the patient's forehead with the other, while an assistant unlocked the articulations of the head holder system. The head was manually extended while maintaining the hinge of extension at the posterior cortex. This was a critical stage of the osteotomy because the extension carried a risk of dislocation of the cervical spine. Once the osteotomy was opened, the head holder system was clamped to secure a new position of the head. Motor evoked potentials were assessed immediately after extension. Then the spine anatomy and degree of correction were evaluated using an $\mathrm{O}$-arm scan. The operating surgeon scrubbed up and returned to the operating table, where stabilization was completed by connecting rods to the cervical pedicle screws with the use of connectors. A gap in the anteriorly created wedge was not packed with bone graft as the potential for bony regrowth and healing is extensive in AS.

\section{Postoperative Course}

The patient was neurologically intact after surgery. Early postoperative CT revealed a $25^{\circ}$ correction of cervical kyphosis in accordance with the preoperative plan (Fig. 5B). The patient was mobilized in a rigid cervical collar, which he wore for 4 months until a control CT scan revealed fully healed fusion (Fig. 5C). The anteriorly based wedge (Fig. 5B) filled in with bone (Fig. 5C). The patient achieved correction of forward gaze according to his preoperative expectations (Fig. 2B and D).

\section{Discussion}

Surgical release of ankylosed chin-on-chest deformity is feasible through a solely posterior approach. With the patient's chin resting over on the chest, ventral exposure of the neck is impossible. The first documented corrections of chin-on-chest deformities were reported in the literature by Mason et al. in 1953 and Urist in 1958. ${ }^{13,14}$ Both authors used extension osteotomy, by opening the anteriorly based wedge in the anterior column. This procedure was achieved through extension of the spine against a fulcrum, localized on the posterior longitudinal ligament or cortex, acting as a hinge.

Mason and Urist adopted the Smith-Petersen osteoclasis osteotomy used for the correction of flexion deformities in the lumbar and thoracic spine but modified it by adding the complete resection of laminae, facet joints. and pedicles. ${ }^{13-15}$ Smith-Petersen performed osteoclasis after only a limited osteotomy through the superior articular process of the vertebra below and the inferior articular process of 

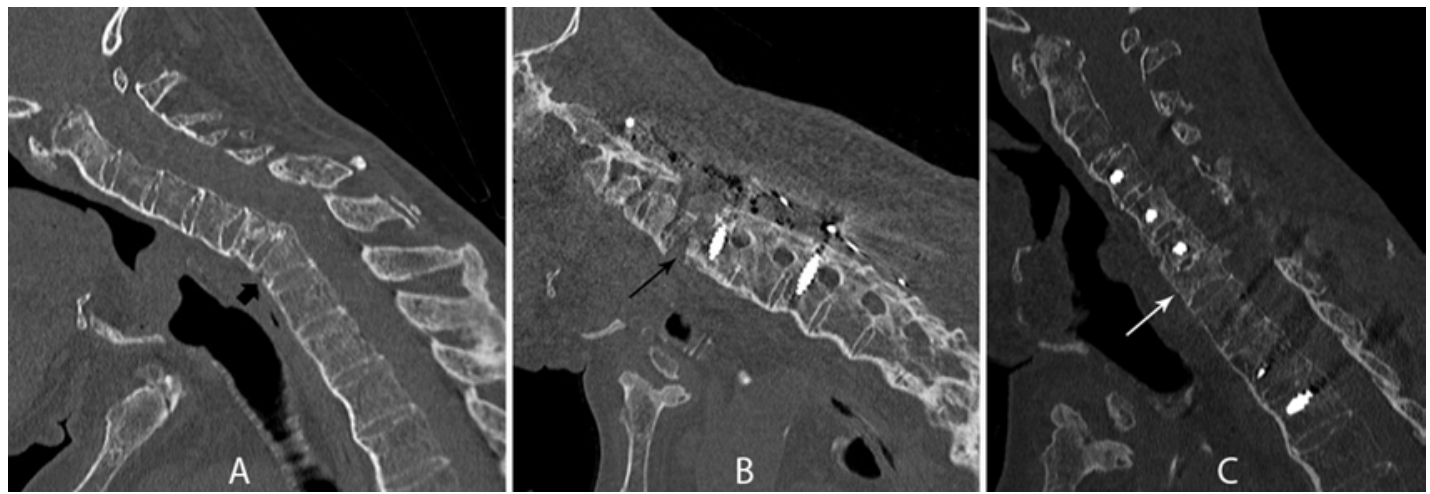

FIG. 5. Pre- and postoperative CT of the cervical spine. A: Preoperative CT. The thick black arrow points to the C7 vertebral body. B: An early postoperative CT scan shows the anteriorly opened wedge (black arrow) after extension of osteotomy. C: CT scan obtained 4 months after surgery shows excellent anterior fusion. The anterior wedge is filled in with bone (white arrow).

the vertebra above..$^{15}$ After osteotomy of the posterior elements, Mason cut the T1 vertebral body crosswise. He achieved complete extension with gradual, postoperative, 2-week traction using Crutchfield tongs. This noninstrumented correction was secured with a plaster-of-paris jacket extending from the head to the pelvis for 7 weeks after the operation, followed by a cervical brace with a head band. Mason's T1 crosswise osteotomy has never been replicated or adapted for corrective surgery of the cervical spine, whereas his idea of postoperative gradual noninstrumented correction was later adapted by several authors. The latter includes the halo thoracic vest, or halo thoracic cast, which allows stepwise controlled extension over a period of a few days after osteotomy.1,4,16,17

Contrary to Mason, Urist employed osteoclasis of the ankylosed intervertebral $\mathrm{C} / \mathrm{T}$ disc instead of cutting through the T1 vertebral body. ${ }^{14}$ Osteoclasis was executed by manual extension of the head after resection of the posterior elements. In contrast to Mason's technique, Urist's opening wedge EO osteotomy found its place in the contemporary treatment of fixed cervical kyphosis. ${ }^{1,3-6,8,9,16-18}$ Some authors combine osteoclasis osteotomy with postoperative gradual correction using a halo thoracic cast or vest without instrumentation. ${ }^{1,4,16,17}$ Other authors execute correction intraoperatively immediately after osteoclasis by securing with external orthosis ${ }^{1,9,16,17}$ or with instrumentation. $3,6,18$

Currently, C7-T1 opening wedge osteoclasis osteotomy is used less often than closing wedge C7 and T1 PSO. ${ }^{711,12,19-24} \mathrm{C} 7$ and T1 PSOs are at the core of surgical correction of fixed chin-on-chest deformity. Our crosswise osteotomy of the vertebral body is surgically less demanding than excision of a posteriorly based wedge, as in PSO. In addition, the angle of correction is better controlled through an opening osteotomy anteriorly rather than a closing posteriorly excised wedge in the vertebral body, as in PSO. In the former, the surgeon can gradually open the osteotomy site until the required angle of correction is achieved. In contrast, the angle of correction in PSO depends on the accuracy of the wedge excision. Once the latter is completed, any inaccuracy of its angle might be irreversible, or remodeling of the posterior wedge might be too troublesome.
The last step in correction of fixed cervical deformities is vertebral column resection, a demanding and rarely used technique carrying a significant risk of complications. ${ }^{25}$ The C7 ECO seems a viable option to currently used osteotomies in the treatment of fixed chin-on-chest deformities in AS.

\section{References}

1. Herbert JJ. Vertebral osteotomy for kyphosis, especially in Marie-Strumpell arthritis; a report on fifty cases. J Bone Joint Surg Am. 1959;41-A(2):291-302.

2. Hoh DJ, Khoueir P, Wang MY. Management of cervical deformity in ankylosing spondylitis. Neurosurg Focus. 2008; 24(1):E9.

3. Khoueir P, Hoh DJ, Wang MY. Use of hinged rods for controlled osteoclastic correction of a fixed cervical kyphotic deformity in ankylosing spondylitis. J Neurosurg Spine. 2008;8(6):579-583.

4. Koller H, Meier O, Zenner J, et al. Non-instrumented correction of cervicothoracic kyphosis in ankylosing spondylitis: a critical analysis on the results of open-wedge osteotomy C7-T1 with gradual Halo-Thoracic-Cast based correction. Eur Spine J. 2013;22(4):819-832.

5. Mehdian S, Arun R. A safe controlled instrumented reduction technique for cervical osteotomy in ankylosing spondylitis. Spine (Phila Pa 1976). 2011;36(9):715-720.

6. Mehdian SMH, Freeman BJC, Licina P. Cervical osteotomy for ankylosing spondylitis: an innovative variation on an existing technique. Eur Spine J. 1999;8(6):505-509.

7. Mummaneni PV, Mummaneni VP, Haid RW Jr, et al. Cervical osteotomy for the correction of chin-on-chest deformity in ankylosing spondylitis. Neurosurg Focus. 2003;14(1):e9.

8. Simmons ED, DiStefano RJ, Zheng Y, Simmons EH. Thirtysix years experience of cervical extension osteotomy in ankylosing spondylitis: techniques and outcomes. Spine (Phila Pa 1976). 2006;31(26):3006-3012.

9. Simmons EH. The surgical correction of flexion deformity of the cervical spine in ankylosing spondylitis. Clin Orthop Relat Res. 1972;86(86):132-143.

10. Etame AB, Than KD, Wang AC, et al. Surgical management of symptomatic cervical or cervicothoracic kyphosis due to ankylosing spondylitis. Spine (Phila Pa 1976). 2008;33(16): E559-E564.

11. Theologis AA, Tabaraee E, Funao H, et al. Three-column osteotomies of the lower cervical and upper thoracic spine: comparison of early outcomes, radiographic parameters, 
and peri-operative complications in 48 patients. Eur Spine J. 2015;24(suppl 1):S23-S30.

12. Tokala DP, Lam KS, Freeman BJ, Webb JK. C7 decancellisation closing wedge osteotomy for the correction of fixed cervico-thoracic kyphosis. Eur Spine J. 2007;16(9):14711478.

13. Mason C, Cozen L, Adelstein L. Surgical correction of flexion deformity of the cervical spine. Calif Med. 1953;79(3): 244-246.

14. Urist MR. Osteotomy of the cervical spine; report of a case of ankylosing rheumatoid spondylitis. J Bone Joint Surg Am. 1958;40-A(4):833-843.

15. Smith-Petersen MN, Larson CB, Aufranc OE. Osteotomy of the spine for correction of flexion deformity in rheumatoid arthritis. J Bone Jt Surg. 1945;27:1-11.

16. Bouchard JA, Feibel RJ. Gradual multiplanar cervical osteotomy to correct kyphotic ankylosing spondylitic deformities. Can J Surg. 2002;45(3):215-218.

17. Hehne HJ, Zielke K. Die zervikale Aufrichtungsosteotomie nach Mason und Urist bei Spondylarthritis ankylopoetica. Akt Rheumatol. 1987;12(2):126-130.

18. Pavlov PW. Correction and stabilisation in ankylosing spondylitis of the cervicothoracic spine. Eur Spine J. 2009;18(8): $1243-1244$

19. Deviren V, Scheer JK, Ames CP. Technique of cervicothoracic junction pedicle subtraction osteotomy for cervical sagittal imbalance: report of 11 cases. J Neurosurg Spine. 2011;15(2): 174-181.

20. Kim KT, Lee SH, Son ES, et al. Surgical treatment of "chinon-pubis" deformity in a patient with ankylosing spondylitis: a case report of consecutive cervical, thoracic, and lumbar corrective osteotomies. Spine (Phila Pa 1976). 2012;37(16): E1017-E1021.

21. Samudrala S, Vaynman S, Thiayananthan T, et al. Cervicothoracic junction kyphosis: surgical reconstruction with pedicle subtraction osteotomy and Smith-Petersen osteotomy. Presented at the 2009 Joint Spine Section Meeting. J Neurosurg Spine. 2010;13(6):695-706.

22. Theologis AA, Bellevue KD, Qamirani E, et al. Asymmetric $\mathrm{C} 7$ pedicle subtraction osteotomy for correction of rigid cervical coronal imbalance secondary to post-traumatic heterotopic ossification: a case report, description of a nove surgical technique, and literature review. Eur Spine J. 2017; 26(suppl 1):141-145.
23. Tobin MK, Birk DM, Rangwala SD, et al. T-1 pedicle subtraction osteotomy for the treatment of rigid cervical kyphotic deformity: report of 4 cases. J Neurosurg Spine. 2017; 27(5):487-493.

24. Wang H, Ma L, Yang D, et al. Comparison of clinical and radiological improvement between the modified trephine and high-speed drill as main osteotomy instrument in pedicle subtraction osteotomy. Medicine (Baltimore). 2015;94(45): e2027.

25. Smith JS, Shaffrey CI, Lafage R, et al. Three-column osteotomy for correction of cervical and cervicothoracic deformities: alignment changes and early complications in a multicenter prospective series of 23 patients. Eur Spine J. 2017; 26(8):2128-2137.

\section{Disclosures}

The authors report no conflict of interest concerning the materials or methods used in this study or the findings specified in this paper.

\section{Author Contributions}

Conception and design: Maciejczak. Acquisition of data: Wolan-Nieroda, Guzik. Analysis and interpretation of data: all authors. Drafting the article: Maciejczak. Critically revising the article: Maciejczak. Reviewed submitted version of manuscript: Maciejczak. Approved the final version of the manuscript on behalf of all authors: Maciejczak. Administrative/technical/ material support: Wolan-Nieroda, Guzik. Study supervision: Maciejczak.

\section{Supplemental Information \\ Videos}

Video 1. https://vimeo.com/442461602.

Video 2. https://vimeo.com/442461751.

\section{Correspondence}

Andrzej Maciejczak: St. Lukas Hospital, Tarnów, Poland. amac@mp.pl. 